\title{
A novel breast cancer cell line initially established from pleural effusion: Evolution towards a more aggressive phenotype
}

\author{
MELANIE SCHMIDT ${ }^{1,8}$, ASHRAF KHAN ${ }^{2}$, ANDRÉ MICHAEL SCHMIDT ${ }^{3}$, BARBARA HEINZE $^{4}$, \\ EVA HACK $^{5}$, JOHANNES WALTENBERGER ${ }^{6}$ and ROLF KREIENBERG ${ }^{7}$
}

\begin{abstract}
${ }^{1}$ Department of Cancer Biology, University of Massachusetts Medical School, LRB-470X, 364 Plantation St., Worcester, MA 01605; ${ }^{2}$ Department of Pathology, University of Massachusetts Medical School, UMass Memorial Medical Center, Three Biotech, One Innovation Drive, Worcester, MA 01605, USA; ${ }^{3}$ Casa-Reha Holding GmbH, Hewlett-Packard-Str. 4, D-61352 Bad Homburg v.d.H.; ${ }^{4}$ Department of Internal Medicine III, University of Ulm, Parkstrasse 11, D-89073 Ulm; ${ }^{5}$ Institute of Pathology Dr Hack, Postfach 1409, D-73504 Schwäbisch Gmünd, Germany; ${ }^{6}$ Department of Interventional Cardiology, University of Maastricht, Peter Debelaan 25, P.O. Box 5800, 6202 AZ Maastricht, The Netherlands;

${ }^{7}$ Department of Gynaecology and Obstetrics, University of Ulm, Prittwitzstrasse 43, D-89075 Ulm, Germany
\end{abstract}

Received September 11, 2006; Accepted October 30, 2006

\begin{abstract}
Many human breast cancer cell lines have been in culture for several years, serving as model systems for studying aspects of breast cancer biology. Molecular alterations might occur in these cells during cultivation, and it remains unknown to which extent findings in these cell lines can be related to human disease. Hereby, we describe the establishment of a breast cancer cell line, MW1, from malignant pleural effusion. We compare expression patterns of several molecular markers in breast biopsy tissue, in cultivated tumor cells derived from pleural effusion reflecting the metastatic state, and in late passages of a lineage derived from the pleural culture. Our data show that expression of estrogen and progesterone receptors was lost in the cultivated tumor cells derived from pleural effusion as shown by immunohistochemical staining. Cytokeratin expression patterns remained luminal. During cultivation, the growth rate of MW1 cells increased
\end{abstract}

Correspondence to: Dr Melanie Schmidt, ${ }^{8}$ Present address: c/o Professor R. Kreienberg, Department of Gynaecology and Obstetrics, University of Ulm, Prittwitzstrasse 43, D-89075 Ulm, Germany

E-mail: melanie_weigand@hotmail.de

Abbreviations: ATCC, American Type Culture Collection; CK, cytokeratin; EGF, epidermal growth factor; ER, estrogen receptor; FGF, fibroblast growth factor; FISH, fluorescence in situ hybridization; HGF, hepatocyte growth factor; HIER, heat-induced epitope retrieval; GAPDH, glyceraldehyde-3-phosphate dehydrogenase; PR, progesterone receptor; VEGF, vascular endothelial growth factor; RT-PCR, reverse transcriptase polymerase chain reaction

Key words: breast cancer, cytokeratin, cadherin, HGF, c-Met, EGFR, integrin $\alpha 634$, VEGF, flt-1, KDR dramatically and the morphology underwent alterations. As shown by Western blotting, E-cadherin expression remained unchanged whereas P-cadherin expression had increased after 4 years of cultivation of the cell line. Integrin $\$ 4$ expression was low in early passages of the pleural effusion whereas the cell line exhibited high expression levels of B4. HGF receptor (c-Met), EGF receptor, VEGF and VEGF receptor-2 (KDR) expression was detectable by semiquantitative RT-PCR and remained unchanged during cultivation. In contrast, VEGF receptor-1 (flt-1) expression showed lower expression after 4 years of cultivation. The cell line migrated towards HGF, but not towards VEGF. This study provides exemplary insight into the molecular metamorphosis tumor cells undergo in vivo or in vitro on their way from the primary tumor via an equivalent of the metastatic state and during the development of a clonal cell line.

\section{Introduction}

Worldwide, breast cancer is the most common cancer and the leading cause of cancer death among women. Despite improvements in breast cancer treatment and a decline in the mortality rate in developed countries, the death rate from breast cancer is still around 38 deaths per 100000 women (1). Prognostic and predictive gene signatures have been identified by microarray technology and point into the direction of individualization of breast cancer management to further improve breast cancer treatment. Molecular fingerprinting is performed on the primary tumor tissue and later on might be applied for treatment of metastatic patients as well, in spite of the fact that molecular alterations might occur during the process of metastasis. Molecular pathology of breast cancer is mostly studied in breast cancer cell lines. To date, a large number of breast cancer cell lines have been established and used worldwide. Most of the established breast cancer cell lines have been in culture for many years and it remains questionable to which extent data derived from these models are relevant for human disease. In this study, we describe the 
development of a breast cancer cell line from pleural effusion and compare the cell line with cultivated tumor cells derived from pleural effusion and with the breast cancer tissue from the patient's primary disease. This longitudinal analysis gives insight into the quantitative or qualitative changes which might occur on the way to metastatic disease in vivo and how further selective pressure might alter molecular features during the process of cultivation. We have developed a breast cancer culture from pleural effusion of a patient and used early passages [6-9] of the culture as equivalent of the metastatic state. We compared these early passages with the primary tumor of the breast biopsy and with late passages [47-65] of a clone derived from the pleural culture.

In our analysis, we focused on a selection of cytokeratins, glycoproteins and growth factors that have been shown to play a role in tumor cell invasion and metastasis and are considered to be prognostic markers for poor clinical outcome.

One reason for the heterogeneity of breast cancers might be their origin from different cell populations within the normal breast. Breast cancer subtypes have been classified inter alia according to their cytokeratin expression pattern. Expression of CK 5 is considered to identify 'basal like' tumors (2) and is associated with a distinct molecular gene expression pattern characterized by ER-, HER2-negativity and EGF receptor expression (3). Expression of the luminal marker CK 7 has been reported to occur predominantly in breast cancer (4). We therefore used CK 5 as a marker for basal cells and CK 7 as a marker for luminal cells.

Cadherins are cell-cell adhesion glycoproteins that are critical for tissue stratification (5). Functional losses of cadherins on the one hand and overexpression on the other have been implicated in carcinogenesis (6). Subfamilies of cadherins show different specific tissue distribution patterns. E-cadherin is expressed in all epithelial cells whereas the expression of $\mathrm{P}$-cadherin in breast tissue is restricted to myoepithelial cells (7). In $\sim 30 \%$ of breast carcinomas P-cadherin expression is upregulated and it has been reported to correlate with poor clinical outcome $(8,9)$. Therefore, we characterized the cadherin expression patterns in early and late passages of MW1 cell line applying Western blotting.

Integrins are glycoproteins that form heterodimers between $\alpha$ and $\beta$ subunits and serve as receptors for extracellular matrix proteins. Integrin $\alpha 6 \beta 4$ is a receptor for some laminin isoforms and has been shown to play a role in tumor cell invasion and metastasis (10-13). a6ß4 expression has been reported to correlate with reduced patient survival in breast cancer $(14,15)$. Since the $\beta 4$ subunit associates exclusively with $\alpha 6$, we compared $\beta 4$ protein expression in early and late MW1 passages.

Hepatocyte growth factor (HGF) plays a role in proliferation, dissociation, migration, and invasion of tumor cells and is a potent angiogenic factor (16). HGF binds to its specific receptor, c-Met. Expression levels of c-Met have been correlated with tumor progression and poor clinical outcome in breast cancer $(17,18)$.

The epidermal growth factor receptor (EGFR) belongs to the type I receptor tyrosine kinases, the ErbB receptors. Apart from EGFR (ErbB1/HER1) the family includes ErbB2 (HER2/neu), ErbB3 (HER3), and ErbB4 (HER4) (19). In many human tumors including breast carcinoma, EGFR is frequently overexpressed (20) and has been correlated with poor clinical outcome in a subset of breast carcinoma patients (21). Monoclonal antibodies directed at EGFR such as gefitinib (ZD1839/Iressa) have proved to inhibit breast cancer growth in vitro and in vivo (22) and are currently under clinical investigation.

Vascular endothelial growth factor (VEGF) expression is crucial for tumor angiogenesis and has been correlated with poor prognosis of breast cancer (23). VEGF as well as its receptors VEGFR-1 (Flt-1), VEGFR-2 (Flk-1/KDR) and neuropilin (NP-1/NP-2) are expressed in breast carcinoma cells $(24,25)$. VEGF acts in a paracrine fashion on endothelial cells and displays autocrine activity on carcinoma cells $(26,27)$. Up to now, it is unclear which role the different VEGF receptors play within the autocrine signaling loop. Therefore, we studied the expression patterns of VEGF and VEGF receptors in early and late passages of MW1 cell line.

\section{Materials and methods}

Clinical history. The breast cancer cell line described herein, designated MW1, was developed from the malignant pleural effusion of a 39-year-old patient suffering from metastatic breast cancer. The patient was diagnosed with breast cancer in 1998 at the age of 36 . She had a grade 2 invasive carcinoma with excessive lymphangiosis carcinomatosa (pT1c multifocal, pN2, M0). The patient underwent breast conservative treatment and axillary dissection. Metastases were found in 8 out of 20 lymph nodes examined. The lymph node metastasis reached up to $1 \mathrm{~cm}$ in diameter. The patient received 6 cycles of standard dose epirubicin $\left(90 \mathrm{mg} / \mathrm{m}^{2}\right)$ and cyclophosphamide $\left(600 \mathrm{mg} / \mathrm{m}^{2}\right)$ i.v. every third week. Postoperative radiation therapy ( $50 \mathrm{~Gy}$ ) was applied to the ipsilateral regional lymph nodes and the breast between cycles 3 and 4 of chemotherapy (sandwich irradiation). Subsequently, the patient received adjuvant tamoxifen treatment $(20 \mathrm{mg}$ per day). In September 2000 the patient presented with bone metastasis and in 2001 lymphangiosis carcinomatosa of the lung was diagnosed. The patient received taxol monotherapy as treatment for distant metastatic disease. Initially, a partial response was achieved but by the end of 2001 the patient suffered from dyspnoea due to pleural effusions. Palliative punction of the pleural cavity were clinically necessary and some of the drained pleural fluid was used for cell culture. Subsequent palliative procedures including pleurodesis did not improve the patient's condition and, unfortunately, she died 3 months later.

Establishment of a primary breast cancer culture. Prior to cultivation of malignant cells, approval therefore was obtained from the patient and the local ethics committee. Fresh pleural effusion was collected, centrifuged and treated as described previously (27). The resulting cell line, designated MW1, was grown continuously upon medium changes thrice weekly in CRML medium (Gibco) containing 10\% fetal bovine serum, $5 \mu \mathrm{g} / \mathrm{ml}$ insulin, penicillin and streptomycin. Confluent cultures were trypsinized for $5 \mathrm{~min}$ at $37^{\circ} \mathrm{C}$ and split into new cultures at ratios of 1:5. The cells were cloned by seeding single cells into 96-well plates and one of the resulting colonies (clone 3) was used for further cultivation and experimental procedures. 
Clone 3 of MW1 had by December 2005 undergone 65 passages. Cryopreservation was done in $90 \%$ culture medium/ 10\% DMSO. To compare the cell line MW1 with established cell lines, T47d, MCF-10A and MDA-MB-231 were grown under conditions recommended for each of the individual cell lines by ATCC. The cell lines PAEC/KDR (28) and LIM 1863 (29) were grown as described previously.

Growth rate assay. MW1 cells in passage 9 (p9) and cloned cells in passage 65 (p65) were plated in 24-well plates at a concentration of 1000 cells/well. Duplicate wells were counted daily for 2 weeks. Values were calculated from the $\log$ phase of the growth curves: Doubling time, tD; MW1 p9, $\mathrm{tD}=\ln 2 / 0.0087 / \mathrm{h}=79.7 \mathrm{~h} ; \mathrm{MW} 1$ clone $3 \mathrm{p} 65, \mathrm{tD}=\ln 2 /$ $0.0179 / \mathrm{h}=38.7 \mathrm{~h}$.

Genetic and immunohistochemical characterization. Karyotyping by multicolour fluorescence in situ hybridization (mFISH) has been described elsewhere $(30,31)$.

Tumor specimens from the primary surgery and paraffinembedded cell pellets of early and late passages of the pleural cell culture and cell line MW1, respectively were immunohistochemically studied. Immunoperoxidase staining was performed on 5- $\mu \mathrm{m}$ sections of formalin-fixed, paraffin-embedded tissue. Slides were first deparaffinized, and rehydrated. Antigen retrieval was carried out as follows: slides were either placed in $0.01 \mathrm{M}$ citrate buffer at $\mathrm{pH} 6.0$, or were placed in $0.001 \mathrm{M}$ EDTA buffer at $\mathrm{pH}$ 8.0. Both sets were heated in a 770-W microwave oven for $14 \mathrm{~min}$. After cooling and rinsing, slides were stained on the Dako Autostainer (Dako, Carpinteria, CA). Endogenous peroxidase activity was blocked by treating tissue sections with Dual Endogenous Enzyme Block (Dako Cytomation, Carpinteria, CA) for $10 \mathrm{~min}$. The slides were then rinsed with Tris-buffer, and the sections were incubated with the primary antibody for $30 \mathrm{~min}$. The sources, dilutions and pretreatment of the antibodies used were: ER (mouse monoclonal, Dako, 1:160, HIER: EDTA pH 8.0), PR (mouse monoclonal, Dako, 1:1280, HIER: EDTA pH 8.0), CK5/6 (mouse monoclonal, Dako, 1:50, HIER: EDTA pH 8.0), CK7 (mouse monoclonal, DAKO, 1:200, HIER: citrate pH 6.0).

Following a buffer rinse, a goat anti-mouse and goat antirabbit-labeled polymer conjugated with horseradish peroxidase [Envision + Dual Link HRP (Dako)] was applied for $30 \mathrm{~min}$. After rinsing, the slides were treated with DAB for $10 \mathrm{~min}$ (Dako) to visualize the end-product, rinsed again, and toned with DAB Enhancer (Dako) for $2 \mathrm{~min}$. Finally, the sections were counterstained with hematoxylin, dehydrated, cleared and mounted with permanent media. For HER-2 immunoassaying, sections were stained with the anti HER-2/neu antibody available from the Dako HercepTest kit (DakoCytomation Carpinteria, CA) on a Dako Autostainer following manufacturer's protocol including pretreatment.

Positivity of the primary antibody was defined as strong brown staining. For estrogen and progesterone receptor, only nuclear staining was considered positive. In the case of CK5/6 and CK7, membrane and cytoplasmic staining was considered positive. HER-2 immunostaining was evaluated using the HerCep Test scoring scheme, in which tumor cell membrane staining was graded as $0,1+, 2+$ and $3+$ based on the intensity of immunostaining.
Semiquantitative reverse transcription-PCR. We isolated mRNA using the One-step RNeasy kit (Qiagen) according to the recommended protocol. The indicated primers and $2 \mu \mathrm{g}$ of RNA were added to the RT-PCR reactions. Reverse transcription was performed at $50^{\circ} \mathrm{C}$ for $30 \mathrm{~min}$, followed by 15 min of $95^{\circ} \mathrm{C}$ for inactivation. The resulting cDNA was then subjected to 35 cycles of amplification, followed by final extension for $10 \mathrm{~min}$ at $72^{\circ} \mathrm{C}$. The primers and conditions for VEGFR-1 (flt-1) and VEGF were described elsewhere (29). For the detection of other transcripts of interest, the following primers and cycling profiles were used: EGFR: sense, 5'-TCT CAG CAA CAT GTC GAT GG-3'; antisense, 5'-TCG CAC TTC TTA CAC TTG CG-3'; $94^{\circ} \mathrm{C}$ for $20 \mathrm{sec}$, $61^{\circ} \mathrm{C}$ for $30 \mathrm{sec}$, and $72^{\circ} \mathrm{C}$ for $45 \mathrm{sec}$, HGF receptor c-Met: sense, 5'-ATA ATG AAG GCC CCC GCT GTG CTT-3'; antisense, 5'-ATT CAT CAC GGC GCG CTT CAC A-3'; $94^{\circ} \mathrm{C}$ for $40 \mathrm{sec}, 58^{\circ} \mathrm{C}$ for $60 \mathrm{sec}, 72^{\circ} \mathrm{C}$ for $90 \mathrm{sec}$, VEGFR-2 (KDR, flk): sense, 5'-ACG CTG ACA TGT ACG GTC TAT-3'; antisense, 5'-GCC AAG CTT GTA CCA TGT GAG-3'; $95^{\circ} \mathrm{C}$ for $45 \mathrm{sec}, 55^{\circ} \mathrm{C}$ for $45 \mathrm{sec}, 72^{\circ} \mathrm{C}$ for $1 \mathrm{~min}$. Normalization with GAPDH was performed for each sample.

Protein expression. Proteins were extracted from cells in RIPA buffer containing EDTA and EGTA (Boston BioProducts) supplemented with protease inhibitor cocktail tablets (Roche Diagnostics). Lysates were centrifuged at $13000 \mathrm{rpm}$ for $15 \mathrm{~min}$ at $4^{\circ} \mathrm{C}$ to remove cellular debris, and the concentration of total cellular protein was determined using Bradford assay. Equal amounts of total cellular protein were treated with SDS-sample buffer and run on polyacrylamide gels, followed by transfer to nitrocellulose membranes (Bio-Rad). Membranes were probed with antibodies against $\beta 4$ integrin (505) (32), E-cadherin (H-108, Santa Cruz), P-cadherin (6A9, Santa Cruz), estrogen receptor $\alpha$ (D-12, Santa Cruz), or B-actin (A-2066, Sigma). Incubation with the primary antibody was followed by probing with a horseradish peroxidase-linked secondary antibody (Mouse immunoglobulins/HRP, Rabbit immunoglobulins/ HRP, Pierce). Enhanced chemiluminescence (Pierce) was detected using X-ray film (HyBlot Cl, Denville).

Migration assay. Migration of breast carcinoma cells was quantified using a modified 48-well Boyden chamber (Nucleopore, Corning Costar Corp.) and polycarbonate membranes with a pore diameter of $5 \mu \mathrm{m}$. Cells were seeded in a concentration of $5 \times 10^{5}$ cells $/ \mathrm{ml}$ in CRML and allowed to migrate for $3 \mathrm{~h}$ at $37^{\circ} \mathrm{C}$ with $5 \% \mathrm{CO}_{2}$. The filter membrane with adherent cells was fixed in $99 \%$ ethanol for $10 \mathrm{~min}$ and stained using Giemsa dye. Thereafter, cells on the upper side of the filter membrane were scraped off and the migrated cells were counted. A total of 15 high power fields from 3 different wells (5 each) was evaluated. Cell migration was stimulated with either HGF (0-100 ng/ml) (Sigma) or VEGF-A165 (0$100 \mathrm{ng} / \mathrm{ml}$ ) (Reliatech).

\section{Results}

The MW1 cell line. We have established a new breast cancer cell line, MW1, from metastatic pleural fluid. The cells have been grown in culture for more than 4 years and grow as an adherent monolayer. In culture, the cells have an appearance of 

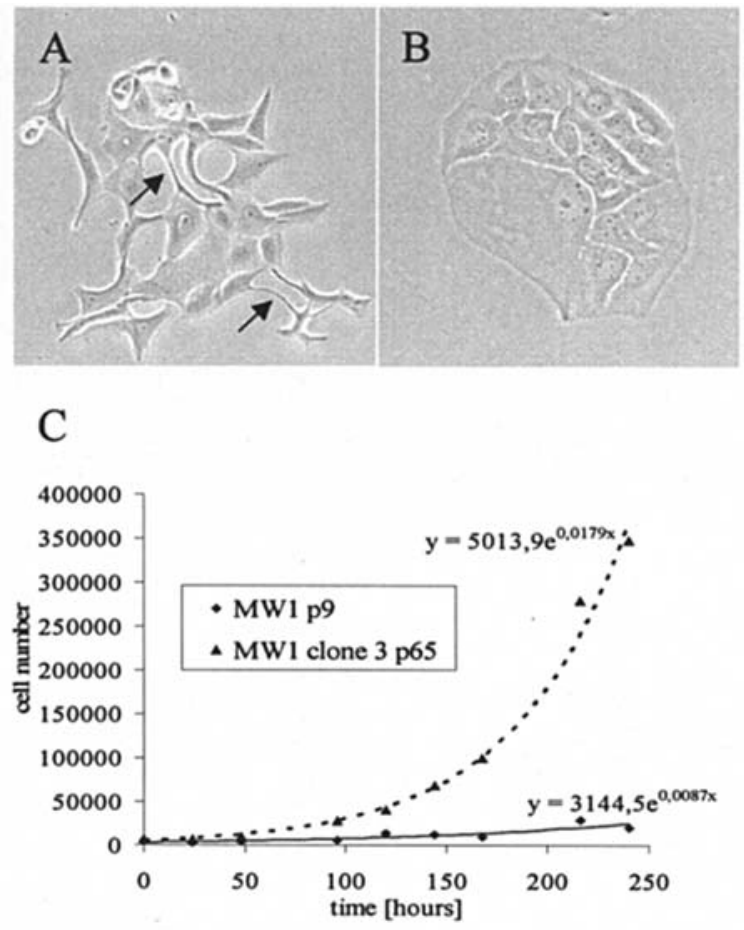

Figure 1. Morphology and growth characteristics of MW1 cell line. A, Early passage (p8) of the primary breast cancer culture MW1 shows epithelial monolayers and typical cellular apophyses that disappeared in later passages (p65). B, Growth curve. MW1 passage 9 and MW1 clone 3 passage 65 were grown and counted daily. Doubling times were calculated from the exponential phase of the growth curves.

medium-sized epithelioid cells with variable nuclear size. In December 2005, the cells had undergone 65 passages, showed continuous growth and had the capacity of recovering from cryopreservation. For comparative purposes, early passages of the pleural culture (passage 3-9) were cryopreserved, thawed 3 years later and compared with passages 49-65 of clone 3 . Morphologically, the cells of early passages of the pleural effusion exhibited the same cobblestone

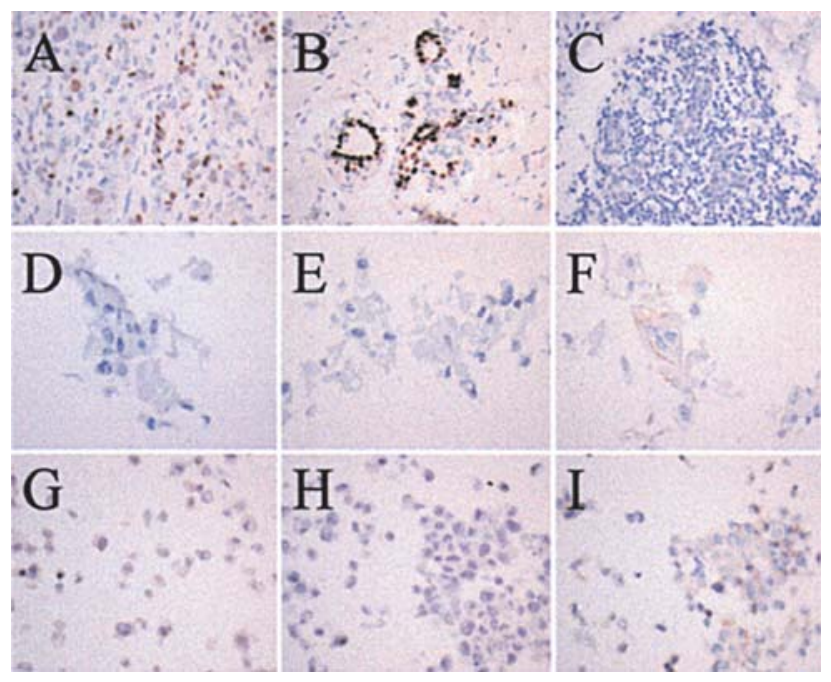

Figure 2. Immunohistochemical characterization of MW1. Immunohistochemical staining of the patients primary tumor (A-C), passage 6 of the primary breast cancer culture MW1 (D-F) and passage 57 of clone 3 of the breast cancer cell line MW1 (G-I). Estrogen receptor (A, D and G), progesterone receptor $(\mathrm{B}, \mathrm{E}$ and $\mathrm{H})$ and $\mathrm{HER} 2(\mathrm{C}, \mathrm{F}$ and $\mathrm{I})$ expression were analyzed.

formation as late passages but were characterized by long cellular apophysises that were lost during continuous growth (Fig. 1A, MW1 p8; B, MW1 clone3 p65). During cultivation doubling times shortened dramatically from $79.7 \mathrm{~h}$ in passage 8 to $38,7 \mathrm{~h}$ in passage 65 (Fig. 1C). The epithelial origin of MW1 was confirmed by pan-cytokeratin staining (27). Multiple colour FISH analysis was performed in early passages of the cultured tumor cells derived from pleural fluid, in order to confirm malignant origin of the cell line. Cells (82) were cytogenetically analyzed and 15 additional carcinoma cells underwent multiple colour FISH analysis. Multiple structural and numeric aberrations were found. Almost all chromosomes showed aberrations: 53,X,i(Xq), $\mathrm{t}(1 \mathrm{p} ; 5),+1, \mathrm{t}(3 \mathrm{q} ; 6), \mathrm{t}(3 \mathrm{q} ; 17),+3, \mathrm{t}(5 \mathrm{q} ; 1),+\operatorname{del}(5 \mathrm{q}), \mathrm{t}(7 \mathrm{p} ; 2)$,

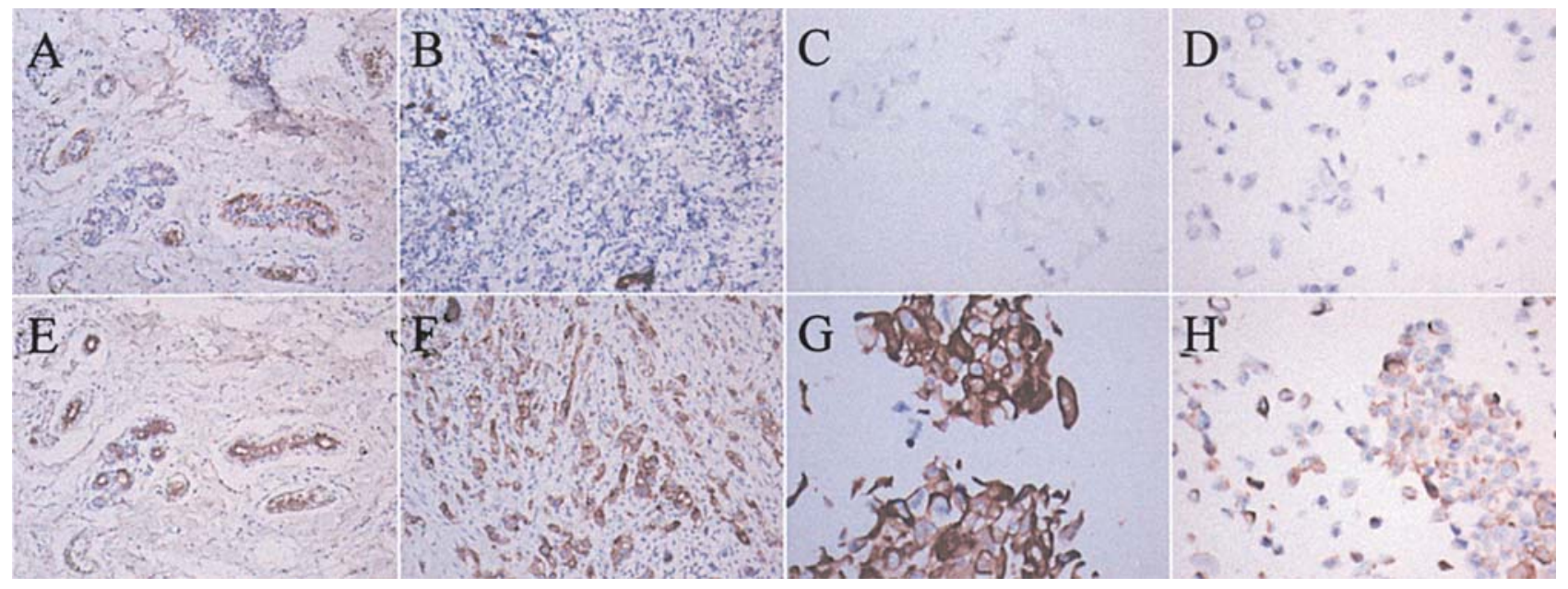

Figure 3. Cytokeratin expression pattern. Immunohistochemical staining for cytokeratins 5/6 (A-D) and cytokeratin 7 (E-H) is shown. Areas of normal breast tissue of the same patient (A and E) are compared to the primary breast cancer tissue (B and F), passage 6 of breast cancer culture MW1 (C and G) as well as passage 57 of clone 3 of MW1 cell line (D and H). 


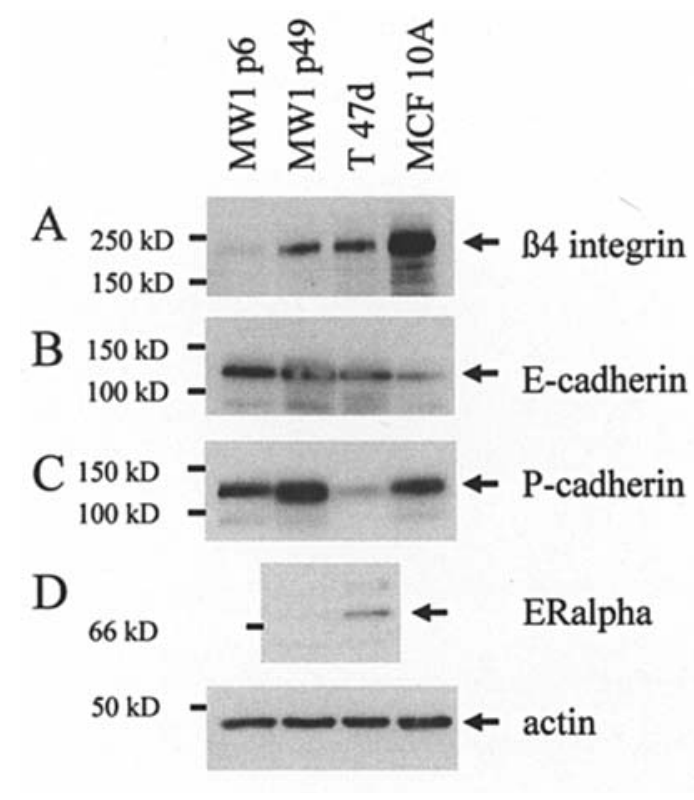

Figure 4. Expression of $\alpha 6 \beta 4$ integrin, cadherins and estrogen receptor $\alpha$. Passage 6 of breast cancer culture MW1, passage 49 of clone 3 of MW1 cell line, breast cancer cell lines T47d and immortalized breast cell line MCF-10A were lysed, immunoprecipitated and blotted against $B 4$ integrin (A), E-cadherin (B), P-cadherin (C) and ER $\alpha$ (D). Protein loading was controlled by blotting for actin on the same membrane.

$+7, \mathrm{t}(8 \mathrm{p} ; 12), \mathrm{t}(8 \mathrm{p} ; 22), \mathrm{i}(9 \mathrm{q}),+\operatorname{del}(10 \mathrm{q}),+\mathrm{t}(13 \mathrm{q} ; 14),-13$, $\mathrm{i}(14 \mathrm{q}),-14, \mathrm{i}(15 \mathrm{q}),+\operatorname{del}(16 \mathrm{q}),-17, \mathrm{t}(18 \mathrm{q} ; 22),+\operatorname{del}(18 \mathrm{q})$, $\mathrm{t}(22 \mathrm{q} ; 16), \mathrm{t}(22 \mathrm{q} ; 18)$.

The genetic changes we identified include chromosomal translocations leading to structural rearrangements in genes and numeric changes causing imbalance in gene dosage. There is growing evidence that mutations in genes controlling chromosome segregation during mitosis causes chromosome instability and leads to aneuploidy in cancers as we see it in the MW1 cell culture (33).

We have established a clonal breast cancer cell line derived from pleural effusion that can be grown as a monolayer under cell culture conditions and serves as in vitro model system for breast cancer.

Immunohistochemical characterization. Immunohistochemical staining of the patient's primary breast tumor revealed positivity for estrogen and progesterone receptors (Fig. 2A and B) but no staining for HER2 (Fig. 2C). Comparison with early passages of tumor cells derived from pleural effusion and with late passages of the clonal cell line showed that the estrogen and progesterone receptor expression was lost in the pleural effusion (Fig. 2D, E, G and H). HER2 was negative in the primary tumor and showed low expression level in the metastatic state and in the cell line. Estrogen receptor negativity of MW1 cell line was confirmed by Western blotting (Fig. 4D).

Subtyping the primary tumor with antibodies specific to cytokeratins of basal origin $(\mathrm{CK} \mathrm{5/6)}$ and to luminal origin (CK 7) showed a predominantly luminal origin of the carcinoma cells (Fig. 3B and F), although single cells within the carcinoma cell structure showed positvity for CK 5/6. Early passages of MW1 (Fig. 3C and G) as well as late passages of clone 3 (Fig. 3D and $\mathrm{H}$ ) stained positive for $\mathrm{CK} 7$, exclusively. Expression levels of $\beta 4$ integrin, $E$ - and $P$-cadherin. The
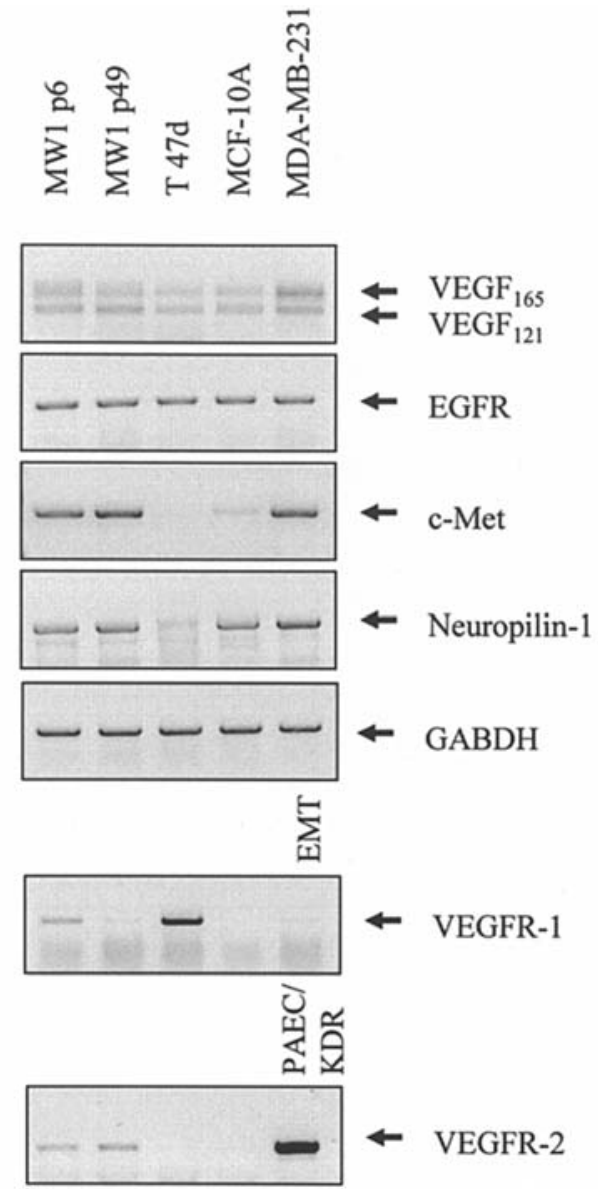

Figure 5. Expression of VEGF, EGFR, c-Met, Neuropilin-1, VEGFR-1 and VEGFR-2. Passage 6 of MW1, passage 49 of clone 3, breast cancer cell lines T47d, MCF-10A and MDA-MB-231 were examined for expression of VEGF, EGFR, c-Met, Neuropilin-1, VEGFR-1 and VEGFR-2 by reverse transcription PCR. GABDH was examined as control. For VEGFR-1 mRNA of colon carcinoma cell line LIM 1863 after induction of epithelial-mesenchymal transition (EMT; 29) was used as positive control. For VEGFR-2 mRNA of a porcine aortic endothelial cell line overexpressing VEGFR-2 (PAEC/ KDR; 28) served as positive control.

expression levels of $\beta 4$ integrin, E- and P-cadherin were compared between early and late passages of MW1 as well as the established breast cancer cell line T47d and the immortalized breast cell line MCF-10A by Western blotting. Early passages of MW1 showed low 34 expression whereas late passages of clone 3 exhibited high expression levels (Fig. 4A). E-cadherin expression remained unchanged in early and late MW1 passages (Fig. 4B) whereas P-cadherin expression increased in late passages (Fig. 4C).

Expression of EGFR, HGFR (c-Met), VEGF, VEGFR-1, VEGFR-2 and neuropilin-1. We analyzed mRNA expression of EGFR, HGFR (c-Met), VEGF, VEGFR-1, VEGFR-2 and neuropilin-1 in passage 6 of MW1, passage 49 of clone 3 , and in the established breast cancer cell lines T47d, MCF-10A, MDA-MB-231. Fig. 5 shows similar VEGF and EGFR mRNA transcription levels for all cell lines tested. Neuropilin-1 levels are likewise essentially similar; with only the cell line T47d exhibiting lower levels of neuropilin-1 transcription. The expression level of VEGFR-1 was high in passage 6 of MW1, but low in passage 49. As positive control we used mRNA from a colon carcinoma cell line after stimulation of 

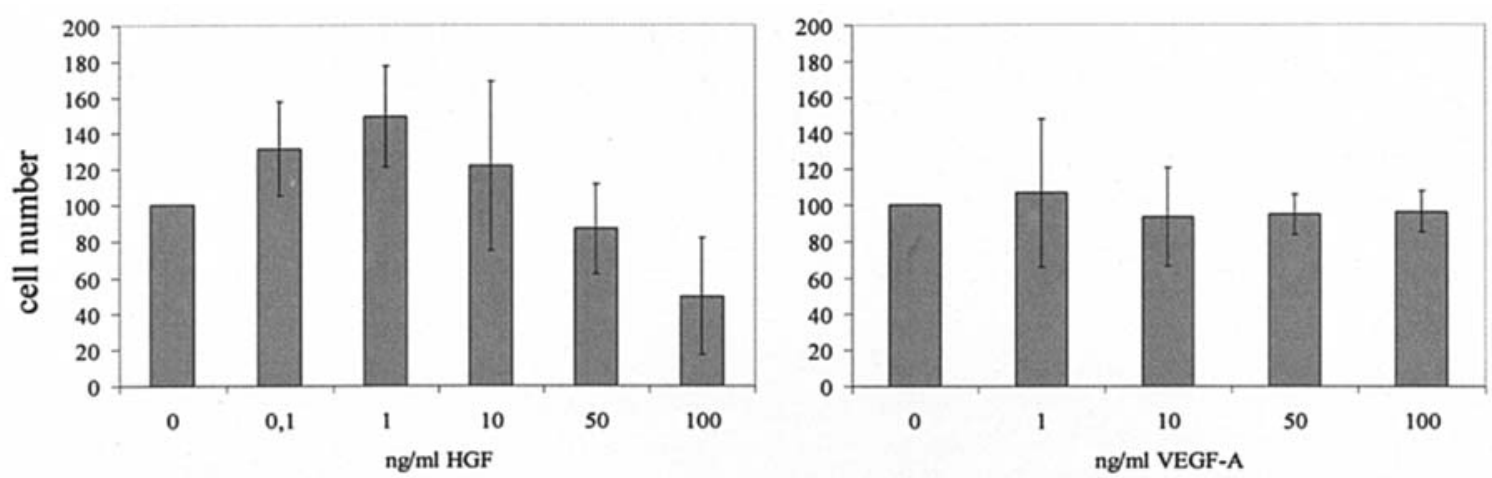

Figure 6. HGF and VEGF-A stimulated chemotaxis of MW1 breast cancer cells. MW1 cells were stimulated with different concentrations of either HGF of VEGF-A using a modified Boyden chamber. A total of 15 high power fields were counted for each sample. Baseline control value was set to $100 \%$.

epithelial-mesenchymal transition (EMT, 29). VEGFR-2 and c-Met were detectable in both MW1 early and late passages and the levels of expression detected showed no alterations after years in culture. As positive control for VEGFR-2, mRNA from a porcine aortic endothelial cell line overexpressing VEGFR-2 was used (PAEC/KDR, 28).

Tumor cell migration. HGF and VEGF-A induced MW1 tumor cell migration was assessed using a modified Boyden chamber assay. The migration of MW1 cells could be stimulated to $149 \%$ with HGF as compared to the $100 \%$ baseline control value. The maximal stimulatory effect was reached at $1 \mathrm{ng} / \mathrm{ml}$ HGF (Fig. 6). An increase of HGF concentration beyond $50 \mathrm{ng} / \mathrm{ml}$ appeared to inhibit tumor cell migration. VEGF-A stimulation showed no effect on MW1 tumor cell migration (Fig. 6).

\section{Discussion}

We herein describe the establishment and characterization of a breast cancer cell line, MW1, derived from pleural effusions of a patient suffering from metastatic breast cancer. To our knowledge, this is the first longitudinal analysis of a cell line over more than 4 years, applying molecular methods to compare the primary tumor of a patient to her pleural effusion and to different passages of a monoclonal cell line that we established. The cell line displays stable growth characteristics under standard culture conditions as recommended by ATCC for breast cancer cell cultures. We ensured that the cells originated from the breast carcinoma by staining for several cytokeratins and by fluorescence in situ hybridization. Genetic changes in numerous chromosomal regions have been described to be involved in the development and progression of breast cancer (34). Some of the changes observed in cell line MW1 involve known loci such as 8p12 (FGFR-1) others do not appear to be associated with established genes. Changes in loci not yet described might be of assistance in the search for critical genes involved in breast cancer development and progression.

A significant number of human breast carcinoma cell lines are available as tumor model systems. Most of the cell lines have been in culture for many years, e.g., the cell line T47d, which was first described in 1979 (35). There are some reports of short-term breast cancer cultures (25) or new breast cancer cell lines $(34,36,37)$. Long-term cultivation of breast cancer cells is difficult and only in a very small percentage of approaches results in a stable cell line $(27,38)$. We assume, that growing tumor cells under culture conditions encourages genetic alterations and selects for cells with rapid doubling times. One challenge described before by Ethier et al (38) is the initially very long doubling time of $70-100 \mathrm{~h}$ that the cells display. This is consistent with the biology of human breast carcinoma in patients. We have confirmed these observations by comparing the growth rate of an early passage of the cell culture to that of a late passage of the cloned cell line MW1. The doubling time reduced to half from 79.7 to $38.7 \mathrm{~h}$. In addition to accelerated growth, the cells also changed their appearance in the culture plates. In particular, characteristic cellular apophyses observed in early passages were lost in late passages. The molecular changes underlying the changes in growth characteristics of the MW1 cell line are as yet unclear.

We used a selection of molecular markers to gain insight into the extent to which the changes occur during cultivation. In addition to changes resulting from cultivation we were also interested in molecular changes occurring in vivo on the way from the primary tumor to the metastatic state reflected by early passages of the pleural culture. In this regard, we were limited by the fact that only paraffin-embedded tissue of the primary tumor was available. Since very early passages [1-5] of a primary culture are inevitably mixed cultures of mesothelial and tumor cells, we had to cultivate the cells for 4-6 months in order to obtain pure tumor cell cultures, as confirmed by staining for cytokeratin 19 (38, staining not shown). Therefore, some changes might have already taken place within the first months of cultivation. Nevertheless, early passages of breast cancer cells derived from pleural effusions closely resemble the metastatic state of breast carcinoma progression.

The primary tumor stained positive for estrogen and progesterone receptor whereas the cultivated metastatic cells as well as the cell line showed no expression of either estrogen or progesterone receptor. This might be due to the antihormonal treatment the patient received in the adjuvant setting. In contrast, HER2/neu expression was not detectable in the primary tumor whereas in the cultivated cells and the cell line, low levels of expression were observed. Both the loss of estrogen and progesterone receptor expression as well 
as gain of HER2/neu expression reflect changes towards a phenotype described as being clinically more aggressive.

As regards cytoceratin expression, the primary tumor expressed predominantly CK 7, as reported for most primary breast cancer tissues (4). Since the luminal and basal staining patterns may show variations between different individuals (39), we stained a section of normal breast tissue of the same patient to ensure that the markers we used could differentiate between luminal and basal cytokeratin expression patterns (Fig. 3A and E). The cytokeratin expression patterns remained luminal in the metastatic state and during cultivation. The staining patterns became more uniform and single cells positive for CK $5 / 6$ as observed in the primary tumor could not be detected in the cultivated cells. We compared E- and P-cadherin expression between passage 6 of the breast cancer culture and passage 49 of the cell line MW1. E-cadherin expression remained unchanged whereas P-cadherin expression increased. This is consistent with the observation that P-cadherin is upregulated in $\sim 30 \%$ of breast carcinomas. The same is true for 34 integrin. In summary, our data suggest that the tumor cells developed a more aggressive phenotype on their way to metastatic disease as well as during cultivation. Hormone receptor expression was lost, weak HER2/neu expression developed, P-cadherin and 34 integrin expression were upregulated. On the way to metastatic disease, this may be due to a selective pressure caused by antihormonal and cytostatic treatment. Apparently, the cell culture conditions also induced selection of the more aggressive phenotype, characterized not only by faster growth but also by harbouring molecular features that have previously been found to correlate with poor clinical outcome. This selection might be due to the fact that only certain cells in a mixed population of the primary tumor are capable of approaching metastatic state and of surviving culture conditions. Alternatively, the selective pressure might enable cells carrying spontaneous mutations towards more aggressive behaviour to survive more efficiently than the original tumor cells.

We were also interested in receptor tyrosine kinase expression patterns and in autocrine signaling loops involving these receptors. VEGF isoforms are known to be expressed by tumor cells and to correlate with poor clinical outcome (23). We found similar mRNA levels of VEGF-A $\mathrm{A}_{165}$ and VEGF- $\mathrm{A}_{121}$ isoforms in early and late passages as well as in all control cell lines tested. In previous studies, we found higher levels of VEGF- $\mathrm{A}_{165}$ in the supernatant of MW1 as compared to established control cell lines applying ELISA (27). This might reflect differences either at the level of protein versus mRNA expression or at the level of VEGF secretion into the culture medium. EGF receptor is known to be overexpressed in breast carcinoma and showed a uniform expression pattern at the mRNA level in the cell lines we tested (Fig. 5). More variations were seen for HGF receptor cMet. HGF is known to be involved in autocrine and paracrine signaling in tumor cells (40), and c-Met expression is considered to be an independent prognostic factor in breast cancer (41). Our data show that both early and late passages of MW1 as well as the established cell line MDA-MB 231 express c-Met whereas the breast cancer cell line T47d and the immortalized breast epithelial cell line MCF-10A display no or merely mRNA levels of c-Met. VEGF produced by tumor cells acts in a paracrine fashion on endothelial cells but also induces autocrine signaling in the tumor itself $(26,27,42)$. The autocrine signaling loop enhances survival and invasion of breast carcinoma cells (26). It is as yet not known which role each of the VEGF receptors VEGFR-1 (flt-1), VEGFR-2 (KDR) and Neuropilin-1 play in the autocrine VEGF signaling loop. We found expression of all of the VEGF receptors in MW1 early and late passages, with VEGFR-1 mRNA levels being lower in late passages of the MW1 cell line. The control cell line T47d expressed VEGFR-1 whereas MCF-10A expressed Neuropilin-1 only. It is unclear why VEGF receptor expression patterns vary between cell lines and what the functional impact thereof might be.

To investigate whether HGF and VEGF signaling have an influence on migration, we studied chemotaxis of MW1 cells towards HGF and VEGF-A. We observed increased migration towards HGF, but no influence on migration could be detected by stimulation with VEGF-A. One possible explanation could be that autocrine VEGF signaling is already saturated in the cells that we have shown to produce VEGF themselves (27, Fig. 5) and that addition of external VEGF has no further effects on signaling.

We established a new cell line that is of special interest for studying the autocrine VEGF signaling loop since VEGF as well as its receptors VEGFR1, VEGFR2 and neuropilin-1 are expressed. We analyzed several molecular markers and if these markers are representative for the patients either primary disease or metastatic state as starting point for further investigations.

Here, we provide an exemplary overview of the molecular changes that may occur on the way from a primary breast cancer lesion via metastatic pleural effusion to the establishment of a stable cell line. This longitudinal analysis might be helpful in relating results gained in breast cancer cell lines to human disease.

\section{Acknowledgements}

We thank Arthur Mercurio for his generous help and for the opportunity to cooperate with his laboratory. We also thank Kurt Weigand, Jennifer Ring, Richard Bates, Dongoo Bae, Keith Merdek and Pia Hantel for valuable discussions and technical help as well as Marianne Madlener for critical review of the manuscript. This study was supported in part by the Medical Faculty of the University of Ulm and in part by the NIH grant CA89209.

\section{References}

1. Berry DA, Cronin KA, Plevritis SK, Fryback DG, Clarke L, Zelen M, Mandelblatt JS, Yakovlev AY, Habbema JD and Feuer EJ: Cancer Intervention and Surveillance Modeling Network (CISNET) Collaborators. Effect of screening and adjuvant therapy on mortality from breast cancer. N Engl J Med 353: 1784-1792, 2005.

2. Moll R, Franke WW and Schiller DL: The catalog of human cytokeratins: patterns of expression in normal epithelia, tumors and cultured cells. Cell 31: 11-24, 1982.

3. Korsching E, Packeisen J, Agelopoulus K, Eisenacher M, Voss R, Isola J, van Diest PJ, Brandt B, Boecker W and Buerger H: Cytognetic alterations and cytokeratin expression patterns in breast cancer: integrating a new model of breast differentiation into cytogenetic pathways of breast carcinogenesis. Lab Invest 82: $1525-1533,2002$. 
4. Abd El-Rehim DM, Pinder SE, Paish CE, Bell J, Blamey RW, Robertson JFR, Nicholson RI and Ellis O: Expression of luminal and basal cytokeratins in human breast carcinoma. J Pathol 203: 661-671, 2004.

5. Takeichi M: Cadherin cell adhesion receptors as a morphogenetic regulator. Science 251: 1451-1455, 1991.

6. Behrens J: Cadherins and catenins: role in signal transduction and tumor progression. Cancer Metastasis Rev 18: 15-30, 1999.

7. Shimoyama Y, Hirohashi S, Hirano S, Noguchi M, Shimosato Y, Takeichi $\mathrm{M}$ and Abe $\mathrm{O}$ : Cadherin cell-adhesion molecules in human epithelial tissues and carcinomas. Cancer Res 49: 2128-2133, 1989.

8. Peralta SA, Knudsen KA, Salazar H, Han AC and Keshgegian AA: P-cadherin expression in breast carcinoma indicates poor survival. Cancer 86: 1263-1272, 1999.

9. Paredes J, Albergaria A, Oliveira JT, Jerónimo C, Milanezi F and Schmitt F: P-cadherin overexpression is an indicator of clinical outcome in invasive breast carcinomas and is associated with $\mathrm{CDH} 3$ promoter hypomethylation. Clin Cancer Res 11: $5869-5877,2005$.

10. Chung J, Bachelder RE, Lipscomb EA, Shaw LM and Mercurio AM: Integrin $\alpha 6 \beta 4$ regulation of elF-4E activity and VEGF translation: a survival mechanism for carcinoma cells. J Cell Biol 158: 165-174, 2002

11. Rabinovitz I, Gibson IK and Mercurio AM: Traction forces mediated by $\alpha 6 \beta 4$ integrin: implications for basement membrane organization and tumor invasion. Mol Biol Cell 12: 4030-4043, 2001.

12. Mercurio AM, Rabinovitz I and Shaw LM: The $\alpha 634$ integrin and epithelial cell migration. Curr Opin Cell Biol 13: 541-545, 2001.

13. Shaw LM, Rabinovitz I, Wang HH-F, Toker A and Mercurio AM: Activation of phosphoinositide 3-OH kinase by the $\alpha 634$ integrin promotes carcinoma invasion. Cell 91: 949-960, 1997.

14. Friedrichs K, Ruis P, Franke F, Gille I, Terpe HJ and Imhof BA: High expression level of $\alpha 6$ integrin in human breast carcinoma is correlated with reduced survival. Cancer Res 15: 901-906, 1995.

15. Tagliabue E, Ghirelli C, Squicciarini P, Aiello P, Colnaghi MI and Menard S: Prognostic value of $\alpha 6 \beta 4$ integrin expression in breast carcinomas is affected by laminin production from tumor cells. Clin Cancer Res 4: 407-410, 1998.

16. Jiang, WG, Hiscox S, Matsumoto K and Nakumura T: Hepatocyte growth factor/scatter factor, the molecular, cellular and clinical implications in cancer. Crit Rev Oncol Hematol 29: 209-248, 1999.

17. Beviglia L, Matsumoto K, Lin CS, Ziober BL and Kramer RH: Expression of the c-met/HGF receptor in human breast carcinoma: correlation with tumor progression. Int J Cancer 74: 301-309, 1997.

18. Camp RL, Rimm EB and Rimm DL: Met expression is associated with poor outcome in patients with axillary lymph node negative breast carcinoma. Cancer 86: 2259-2265, 1999.

19. Olayioye MA, Neve RM, Lane HA and Hynes NE: The ErbB signalling network: receptor heterodimerization in development and cancer. EMBO J 19: 3159-3167, 2000.

20. Salomon D, Brandt R, Ciardiello F and Normanno N: Epidermal growth factor-related peptides and their receptors in human malignancies. Crit Rev Oncol Hematol 19: 183-232, 1995.

21. Buchholz TA, Tu X, Kian Ang K, Esteva FJ, Kuerer HM, Pusztai L, Cristofanilli M, Singletary SE, Hortobagyi GN and Sahin AA: Epidermal growth factor receptor expression correlates with poor survival in patients who have breast carcinomas treated with doxorubicin-based neoadjuvant chemotherapy. Cancer 104: 676-681, 2005.

22. Moulder SL, Yakes M, Muthuswamy SK, Bianco R, Simpson JF and Arteaga CL: Epidermal growth factor receptor (HER1) tyrosine kinase inhibitor ZD1839 (Iressa) inhibits HER2/neu (erbB2)-overexpressing breast cancer cells in vitro and in vivo. Cancer Res 61: 8887-8895, 2001.

23. Linderholm BK, Lindh B, Beckman L, Erlanson M, Edin K, Travelin B, Bergh J, Grankvist K and Henriksson R: Prognostic correlation of basic fibroblast growth factor and vascular endothelial growth factor in 1307 primary breast cancers. Clin Breast Cancer 4: 340-347, 2003.
24. De Jong JS, van Diest PJ, van der Valk P and Baak JP: Expression of growth factors, growth inhibiting factors, and their receptors in invasive breast cancer. I: An inventory in search of autocrine and paracrine loops. J Pathol 184: 44-52, 1998.

25. Speirs V, Green AR, Walton DS, Kerin MJ, Fox JN, Carleton PJ, Desai SB and Atkin SL: Short-term primary culture of epithelial cells derived from human breast tumours. Br J Cancer 78 : 1421-1429, 1998.

26. Bachelder RE, Crago A, Chung J, Wendt MA, Shaw LM, Robinson G and Mercurio AM: Vascular endothelial growth factor is an autocrine survival factor for Neuropilin-expressing breast carcinoma cells. Cancer Res 61: 5736-5740, 2001.

27. Weigand M, Hantel P, Kreienberg R and Waltenberger J: Autocrine vascular endothelial growth factor signalling in breast cancer. Evidence from cell lines and primary breast cancer cultures in vitro. Angiogenesis 8: 197-204, 2005.

28. Waltenberger J, Claesson-Welsh L, Siegbahn A, Shibuya M and Heldin C-H: Different signal transduction properties of KDR and Flt1, two receptors of vascular endothelial growth factor. J Biol Chem 269: 26988-26995, 1994.

29. Bates RC, Goldsmith JD, Bachelder RE, Brown C, Shibuya M, Oettgen P and Mercurio AM: Flt-1-Dependent survival characterizes the epithelial-mesenchymal transition of colonic organoids. Curr Biol 13: 1721-1727, 2003.

30. Greulich KM, Kreja L, Heinze B, Rhein AP, Weier HG, Bruckner M, Fuchs P and Molls M: Rapid detection of radiationinduced chromosomal aberrations in lymphocytes and hematopoietic progenitor cells by mFISH. Mutat Res 452: 7381,2002 .

31. Speicher MR, Ballard SG and Ward DC: Karyotyping human chromosomes by combinatorial multi-fluor FISH. Nat Genet 12: 368-375, 1996.

32. Rabinovitz I, Toker A and Mercurio AM: Protein kinase Cdependent mobilization of the alpha6beta4 integrin from hemidesmosomes and its association with actin-rich cell protrusions drive the chemotactic migration of carcinoma cells. J Cell Biol 146: 1147-1160, 1999.

33. Sen S: Aneuploidy and cancer. Curr Opin Oncol 12: 82-88, 2000.

34. Forozan F, Veldman R, Ammerman CA, Parsa NZ, Kallioniemi A, Kallioniemi OP and Ethier SP: Molecular cytogenetic analysis of 11 new breast cancer cell lines. Br J Cancer 81: 1328-1334, 1999.

35. Keydar I, Chen L, Karby S, Weiss FR, Delarea J, Radu M, Chaitcik S and Brenner HJ: Establishment and characterization of a cell line of human breast carcinoma origin. Eur J Cancer 15: 659-670, 1979.

36. Tanner M, Kapanen AI, Junttila T, Raheem O, Grenman S, Elo J, Elenius K and Isola J: Characterization of a novel cell line established from a patient with Herceptin-resistant breast cancer. Mol Cancer Ther 3: 1585-1592, 2004.

37. Vazquez SM, Mladovan A, Garbovesky C, Baldi A and Luthy IA: Three novel hormone-responsive cell lines derived from primary human breast carcinomas: functional characterization. J Cell Physiol 199: 460-469, 2004.

38. Ethier SP, Mahacek ML, Gullick WJ, Frank TS and Weber BL: Differential isolation of normal luminal mammary epithelial cells and breast cancer cells from primary and metastatic sites using selective media. Cancer Res 53: 627-635, 1993.

39. Gusterson BA, Ross DT, Heath VJ and Stein T: Basal cytokeratins and their relationship to the cellular origin and functional classification of breast cancer. Breast Cancer Res 7: 143-148, 2005.

40. Tuck ABTuck AB, Park M, Sterns EE, Boag A and Elliott BE: Coexpression of hepatocyte growth factor and receptor (Met) in human breast carcinoma. Am J Pathol 148: 225-232, 1996.

41. Ghoussoub RA, Dillon DA, D'Aquila T, Rimm EB, Fearon ER and Rimm DL: Expression of c-met is a strong independent prognostic factor in breast carcinoma. Cancer 82: 1513-1520, 1998.

42. Soker S, Takashima S, Miao HQ, Neufeld G and Klagsbrun M: Neuropilin-1 is expressed by endothelial and tumor cells as an isoform-specific receptor for vascular endothelial growth factor. Cell 92: 735-745, 1998. 